\title{
Effect of Combined Aluminum-silicon Synergistic Impregnation and Heat Treatment on the Thermal Stability, Chemical Components, and Morphology of Wood
}

\author{
Lijie Qu, Zhenyu Wang, Jing Qian, Zhengbin He,* and Songlin Yi *
}

\begin{abstract}
Wood is flammable and consumes a lot of energy during processing. To improve this material, wood was pretreated via aluminum sulfate-sodium silicate synergistic impregnation combined with heat treatment. The wood before and after pretreatment was analyzed through the solids weight changes, thermogravimetric and differential thermogravimetric analyses, somke density, scanning electron microscopy, and Fourier-transform infrared spectroscopy. The experimental results showed that the combined treatment could reduce the energy consumption of the heat treatment by catalyzed thermal degradation with aluminum-silicon synergistic impregnation. This procedure improved the thermal stability of the wood. Meanwhile, the combined treatment resolved the problem of increased smoke release caused by the impregnation of aluminum sulfate-sodium silicate modification reagents.
\end{abstract}

Keywords: Aluminum sulfate; Heat treatment; Sodium silicate; Smoke density; Thermal stability

Contact information: Beijing Key Laboratory of Wood Materials and Engineering, College of Materials Science and Technology, Beijing Forestry University, No. 35, Qinghua East Road, Haidian District, 100083, Beijing, P.R. China; *Corresponding authors: hzbbjfu@126.com; ysonglin@126.com

\section{INTRODUCTION}

Wood is a natural and renewable lignocellulosic material characterized by a high strength-to-weight ratio, low energy cost for processing, good environmental sustainability (Cui et al. 2017; Wang et al. 2018), natural degradation, and being environmentally friendly (Schwartz et al. 2018). Wood has thus been extensively used in construction, buildings, and furniture (Okon et al. 2017; Hosseinpourpia et al. 2018) for many years. As a lignocellulosic material, wood mainly consists of hemicellulose, lignin, and cellulose (Nishimura et al. 2018), and it is combustible. Wood is also prone to hygroexpansion and anisotropy (Skaar 1988), i.e. has a low dimensional stability. These characteristics dramatically shorten the service life and value of wood products, thus limiting its wider applications.

At present, to improve fire retardancy, wood can be chemically modified with the impregnation of flame retardants (Seo et al. 2018). Compounds containing boron, phosphorus, bromine, chlorine, nitrogen, or a combination of two or more of these elements have reportedly improved the thermal stability of wood (Lu et al. 2015; Park et al. 2015; Elvira-León et al. 2016; Jebrane et al. 2018). Slight improvements have been observed with these treatments because the synergistic effect of nitrogen, phosphorus, and boron promotes char formation (Lowden et al. 2013). However, increasing awareness of the environmental issues and consumer safety of flame retardants indicates that the use of conventional boron and formaldehyde may decline (Candan et al. 2013; Chen et al. 2018). 
A current challenging goal in the industry is the use of efficient and low toxic compounds as flame retardants to reduce the use of halogenated flame retardants (Zhao and Deng 2006).

As one kind of inorganic flame retardant, silicon flame retardants have the advantages of a low heat release, low release of carbon monoxide (Hamdani et al. 2009), and environmentally friendly and multi-functional characteristics. Additionally, they can be impregnated into the pyrolyzed areas of the wood combustion layer. When wood is treated by inorganic silicon flame retardants, the smoke concentration during combustion is low, heat release is reduced, and flame spread is slow. Under a normal temperature and pressure, treatment of wood with sodium silicate not only improves the flame retardancy, but it also increases the degradation resistance of the wood (Pereyra and Giudice 2009; Canosa et al. 2011; Jiang et al. 2018). As silicon reagents are prone to evaporation and can be easily lost and because the strong alkaline conditions have an impact on the cellulose and lignin components, the sodium silicate modifier needs to be compounded with other reagents. Aluminum sulfate is attractive to researchers, as it has the advantages of an ultralow toxicity, wide source, and low cost. Meanwhile, preferentially impregnating aluminum sulfate can neutralize the basicity of water glass (sodium silicate). An acidic environment can promote the thermal degradation of wood and accelerate the formation of a carbon layer when heated, which thereby reduces the time and temperature required for heat treatment and reduces the energy consumption (Zhou et al. 2000; Heng 2009; Qu et al. 2011). The precipitation product of aluminum sulfate and sodium silicate (mainly including aluminum hydroxide, aluminum silicate, and sodium sulfate) also has good thermal stability, which can protect the carbon layer (Furuno et al. 1993; Liang et al. 2013). However, the moisture absorption of wood modified by such composite inorganic agents increases, which affects its dimensional stability.

Heat treatment, as an environmentally friendly approach, can improve some wood properties, such as by enhancing the hygroscopicity and dimensional stability, reducing the wettability (Gao et al. 2016; Hidayat et al. 2017), and increasing the durability (Li et al. 2015; Humar et al. 2016; Yang et al. 2018), thus improving the wood's properties. However, heat treatment involves energy and time consumption because of the high temperatures used.

In this study, wood was first impregnated with aluminum sulfate, followed by impregnation with sodium silicate. Subsequent heat treatment led to an improvement in the wood thermal stability and a decrease in the release of smoke. This study aims to lay the foundation for improving the flame retardancy of Paulownia and provide a promising modification reagent.

\section{EXPERIMENTAL}

\section{Materials}

Paulownia (Paulownia elongata) sapwood samples that were straight-grained, knot-free, and with no visible defects were provided by Guangxi Ushine Home Products Ltd (Guangxi, China). The dimensions of the samples were $20 \mathrm{~mm} \times 20 \mathrm{~mm} \times 20 \mathrm{~mm}$ and $25 \mathrm{~mm} \times 25 \mathrm{~mm} \times 20 \mathrm{~mm}$, and all of the samples were dried at $80^{\circ} \mathrm{C}$ to a constant weight. The final weight of each sample was recorded, and the samples were divided into Groups A, B, C, and D. Each group consisted of 20 samples. All of the chemical reagents used were purchased from Sinopharm Chemical Reagent Co. Ltd. (Shanghai, China). 


\section{Methods}

Impregnation pretreatment

The wood samples in Group A were immersed in distilled water. The Group B samples were treated with $26.7 \%$ aluminum sulfate solution, and under the vacuum at 0.06 $\mathrm{MPa}$. The vacuum was released for $30 \mathrm{~s}$ every $3 \mathrm{~min}$, and this vacuum-release cycle was maintained for $30 \mathrm{~min}$. Then, the $\mathrm{Al}_{2}\left(\mathrm{SO}_{4}\right)_{3}$-treated samples were placed into a $30 \%$ sodium silicate solution for $12 \mathrm{~h}$ under atmospheric pressure. Meanwhile, the control group (Group A) samples remained immersed in distilled water under the same conditions. Groups $C$ and D were pretreated under the same conditions as Groups A and B, respectively. After impregnation, all of the wood samples were dried at $80{ }^{\circ} \mathrm{C}$ to a constant weight. After all of the samples were dried, the mass of each was measured.

\section{Heat treatment}

After the samples were dried at $80{ }^{\circ} \mathrm{C}$, only Groups $\mathrm{C}$ and $\mathrm{D}$ were placed in an oven at $180{ }^{\circ} \mathrm{C}$ for $4 \mathrm{~h}$ with steam protection to determine whether aluminum-silicon impregnation would affect the thermal stability of the samples. The specific conditions for each group are shown in Table 1.

Table 1. Specific Treatment Conditions for Each Group

\begin{tabular}{ll}
\hline Expt. No & \multicolumn{1}{c}{ Treatment } \\
\hline Group A & Control group \\
Group B & Only aluminum-silicon impregnation treatment \\
Group C & Only $180^{\circ} \mathrm{C}$ heat treatment \\
Group D & Aluminum-silicon impregnation treatment $+180^{\circ} \mathrm{C}$ heat treatment \\
\hline
\end{tabular}

Changes in weight

The solids weight percentage gain (WPG) of the samples was measured using Eq. 1,

$$
\mathrm{WPG}(\%)=\frac{W_{i}-W_{0}}{W_{0}} \times 100 \%
$$

where $W_{\mathrm{i}}$ is the dry weight $(\mathrm{g})$ at $80{ }^{\circ} \mathrm{C}$ of the samples after aluminum sulfate-sodium silicate synergistic impregnation, and $W_{0}$ is the dry weight $(\mathrm{g})$ of the untreated samples at $80{ }^{\circ} \mathrm{C}$. Solids weight percentage loss (WPL) was also determined for all treated samples using Eq. 2,

$$
\mathrm{WPL}(\%)=\frac{W_{i}-W_{h}}{W_{i}} \times 100 \%
$$

where $W_{\mathrm{i}}$ is the dry weight $(\mathrm{g})$ at $80{ }^{\circ} \mathrm{C}$ of the samples after aluminum sulfate-sodium silicate synergistic impregnation, and $W_{\mathrm{h}}$ is the weight $(\mathrm{g})$ of the aluminum sulfate-sodium silicate impregnation treated samples after $180{ }^{\circ} \mathrm{C}$ heat treatment.

\section{Thermogravimetric analysis}

The thermal properties of the untreated and treated Paulownia wood samples were measured using a Netzsch STA449F3 computerized thermobalance (NETZSCH Gerätebau $\mathrm{GmbH}$, Munich, Germany). For this analysis, the samples were heated from $0{ }^{\circ} \mathrm{C}$ to 900 ${ }^{\circ} \mathrm{C}$ at a constant heating rate of $10{ }^{\circ} \mathrm{C} / \mathrm{min}$ in a nitrogen atmosphere $(100 \mathrm{~mL} / \mathrm{min})$. 


\section{Smoke density test}

The smoke emission characteristics of the samples were measured according to (GB/T 8627-2007) by a smoke density test (JCY-2, Jiangning, Nanjing, China), for which each sample was cut into the dimensions of $25 \mathrm{~mm} \times 25 \mathrm{~mm} \times 6 \mathrm{~mm}$.

\section{Fourier-transform infrared spectroscopy}

Fourier-transform infrared (FTIR) spectroscopy was used to examine the surface chemical compositions of the untreated Paulownia wood and the Paulownia wood that had undergone the impregnation treatment. The control group and impregnation-treated group were separately milled into 200-mesh-sized particles and then mixed with potassium bromide pellets at a ratio of 1:100 (by weight) for FTIR spectroscopy (Tensor 27, Bruker, Karlsruhe, Germany). The samples were then analyzed over a scanning range of $4000 \mathrm{~cm}^{-}$ ${ }^{1}$ to $400 \mathrm{~cm}^{-1}$ at a resolution of $4 \mathrm{~cm}^{-1}$ with 32 scans.

\section{Scanning electron microscopy}

The samples that were dried to a constant weight were randomly selected from both the control and impregnation-treated groups and cut to the dimensions $5 \mathrm{~mm} \times 5 \mathrm{~mm} \times 2$ $\mathrm{mm}$. Each of the untreated and treated samples was fixed on conductive adhesives and coated with gold for the scanning electron microscopy (SEM) analysis (Hitachi S-3400N II, Tokyo, Japan).

\section{RESULTS AND DISCUSSION}

\section{Changes in Weight}

Notable WPGs were observed for the samples that underwent the aluminum sulfate-sodium silicate synergistic impregnation treatment.

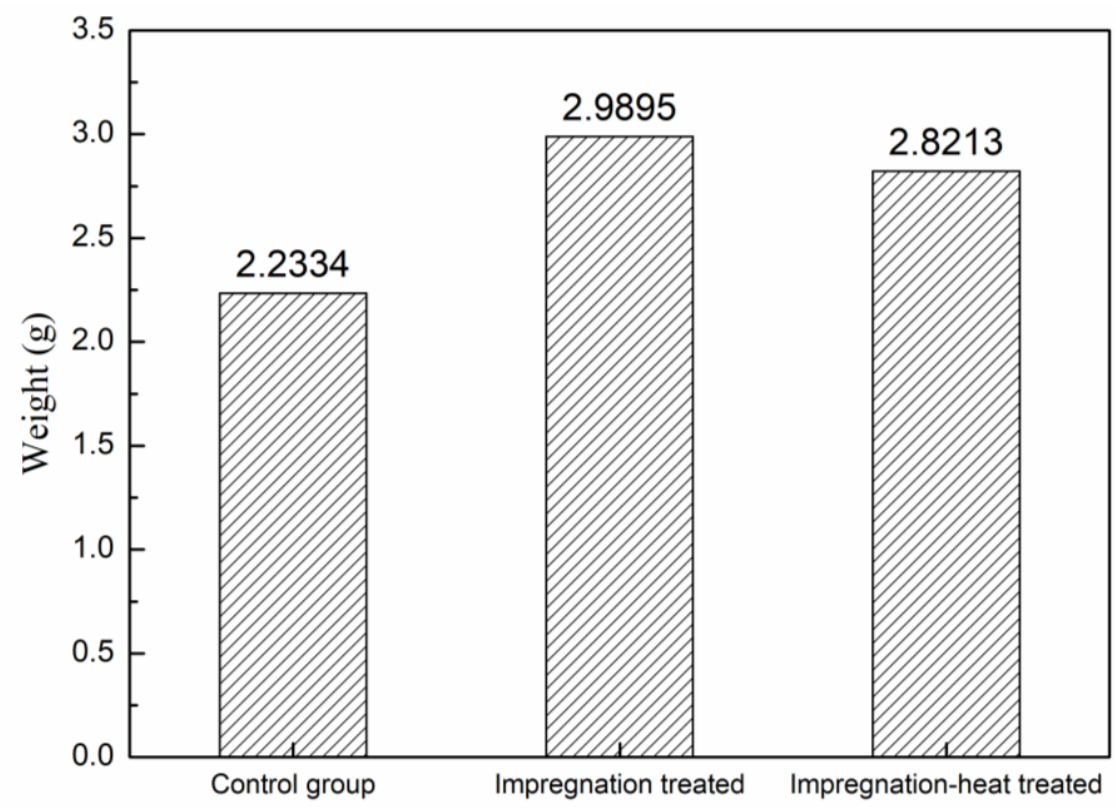

Fig. 1. Weight changes of the samples; Control group: without aluminum-silicon impregnation/ without heat treatment; Impregnation treated: with aluminum-silicon impregnation/without heat treatment; Impregnation-heat treated: with aluminum-silicon impregnation/with heat treatment 
The WPGs of the impregnation-treated samples were higher by $33.8 \%$ relative to that of the control group, but WPLs is very small in impregnation-heat treated samples, only $5.6 \%$ relative to that of the impregnation treated samples. This result revealed that the aluminum sulfate was successfully impregnated into the wood samples. The reason for the increased WPGs may be due to the $\mathrm{Al}^{3+}$ ions, which could penetrate the inner layers of the fibrous cell walls through the nanometer voids in the fibers. Also, $\mathrm{Al}^{3+}$ ions can easily bridge with hydroxyl-containing substances, as wood contains a large number of hydroxyl groups and the silicic molecules produced by the hydrolysis of sodium silicate also contain hydroxyl groups (Benalycherif and Girault 2010; Irfan et al. 2013). During the impregnation process, a sodium silicate solution was added to form thicker aluminumsilicon compounds (mainly including aluminum hydroxide, sodium sulfate, aluminum silicate) by an adsorption bridging effect (Cai 2015). Subsequently, aluminum-silicon compounds were deposited in the wood (Gong et al. 2013). From a macroscopic view, the weight gain rate of the sample increased.

\section{Thermogravimetric Analysis}

Wood is mainly composed of cellulose, hemicellulose, lignin, and some extractives. Thermal degradation of wood can be regarded as the superposition of the three major pyrolysis processes. Figure 2 shows that the main reaction zone for the specimen without the impregnation treatment had a shoulder and an intense peak in the DTG curve. This was attributed to the different thermal degradation regions of the three wood components.

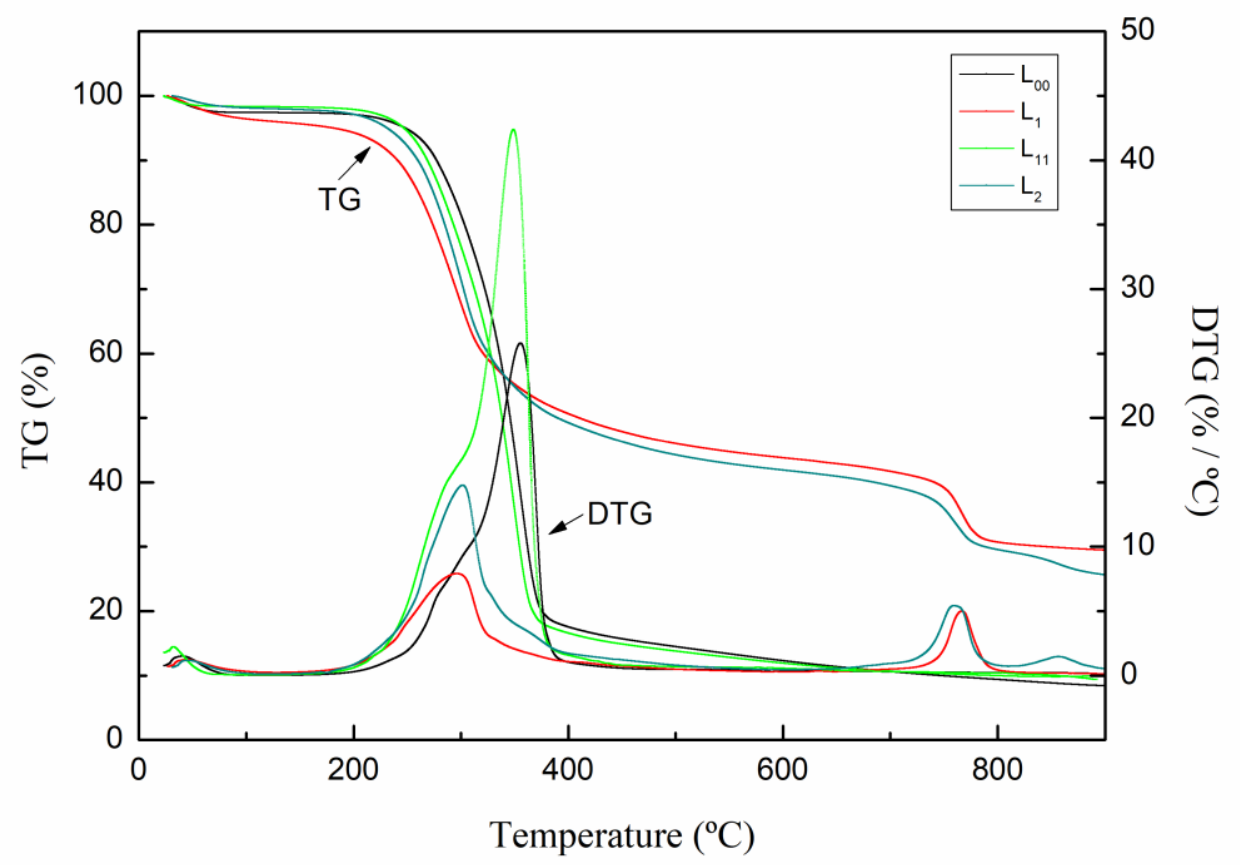

Fig. 2. TG and DTG curves of the samples; Lo0: control group; $L_{1}$ : with aluminum-silicon impregnation/without heat treatment; $L_{11}$ : without aluminum-silicon impregnation/with heat treatment; and $\mathrm{L}_{2}$ : with aluminum-silicon impregnation/with heat treatment

Thermal degradation of hemicellulose occurs at a lower temperature, and mostly starts at less than $350{ }^{\circ} \mathrm{C}$; thermal degradation of cellulose mainly occurs at $315^{\circ} \mathrm{C}$ to 400 ${ }^{\circ} \mathrm{C}$; and thermal degradation of lignin occurs between $250{ }^{\circ} \mathrm{C}$ and $900{ }^{\circ} \mathrm{C}$ (Liao et al. 2008). 
Therefore, the shoulder peak mainly corresponded to the thermal degradation of hemicellulose, whereas the main peak corresponded to the thermal degradation of cellulose. Meanwhile, no shoulder peak was observed in the impregnation-pretreated wood. This finding indicated that heat treatment after the impregnation pretreatment effectively degraded part of the hemicellulose in the wood, which can help to improve the wood performance.

The selection of $180{ }^{\circ} \mathrm{C}$ as the treatment temperature was based on the consideration of the energy consumption problem and the influence of a high temperature on the wood color. Compared with $\mathrm{L}_{00}$ (control group), the TG and DTG curves of $\mathrm{L}_{11}$ (aluminumsilicon impregnation/without heat treatment) moved slightly toward the low temperature region and the maximum heat loss rate was greatly increased. This result was attributed to the heat treatment of wood at $180{ }^{\circ} \mathrm{C}$. During heat treatment, part of the hemicellulose might have decomposed into acids, and the acids that remained inside of the wood, where they accelerated further thermal degradation of the material. Moreover, the degradation of hemicellulose increased the internal space in the wood, thus facilitating pyrolysis (Chen et al. 2012).

The results from the thermal analysis revealed that the onset and offset temperatures of the main reaction zone for $\mathrm{L}_{00}$ were almost identical to those of $\mathrm{L}_{1}$, and the peaks of the DTG curves for $\mathrm{L}_{1}$ shifted to a slightly lower temperature zone. This shift may have been because the precipitates produced during the impregnation process clogged voids in the wood and prevented further reactions. Hence only a small amount of aluminum sulfate remained in the wood, which promoted the thermal degradation of wood, produced a carbon layer, and had similar results to those of previous studies (Wang et al. 2017; Hosseinpourpia et al. 2018). However, the weight loss of $\mathrm{L}_{1}$ in the main reaction zone was smaller than that for $\mathrm{L}_{00}$. When the temperature was $380^{\circ} \mathrm{C}$, the weight loss in $\mathrm{L}_{00}$ was $81 \%$, whereas in $\mathrm{L}_{1}$ it was only $52 \%$, which was a decrease of $29 \%$. Compared with the sharper DTG peaks of $\mathrm{L}_{00}, \mathrm{~L}_{1}$ showed wide and flat DTG peaks. Moreover, the maximum mass loss rate in this reaction zone apparently decreased from $25.8 \%$ to $7.9 \%$. This reduction could have been because of the precipitated product, which formed silicon compounds that contain $\mathrm{Si}-\mathrm{O}-\mathrm{C}$ and $-\mathrm{Si}-\mathrm{C}$ - bonds during the thermal degradation process (Ogiso and Saka 1994). Silicon compounds can effectively protect the carbon layer and the high-temperature-resistant precipitated product can coat the wood powder to act as a physical barrier and also affect dilution. This occurrence led to a reduction in the thermal degradation and weight loss rates, as well as an increase in the thermal stability of the material. From $380{ }^{\circ} \mathrm{C}$ to $720{ }^{\circ} \mathrm{C}$, only $11 \%$ of the weight of $\mathrm{L}_{1}$ was lost at a considerably low rate. These results indicated an improvement in the stability of the char residue. Figure 1 shows that in the $720{ }^{\circ} \mathrm{C}$ to $800{ }^{\circ} \mathrm{C}$ range, $\mathrm{L}_{1}$ had a secondary reaction region. The occurrence of this phenomenon may have been because of the high temperature, which caused precipitates to break down (Hu 2012; Gong et al. 2013; Liang et al. 2013; Zhao and $\mathrm{Xu}$ 2018).

In the main reaction zone, the onset and offset temperatures for $L_{2}$ and $L_{11}$ were basically the same. Although the maximum weight loss rate of the $\mathrm{L}_{2}$ samples slightly shifted to the low-temperature zone, the maximum mass loss rate was considerably lower. When the temperature was $380{ }^{\circ} \mathrm{C}$ (offset temperature), the maximum mass loss rate of $\mathrm{L}_{11}$ was $42.68 \% /{ }^{\circ} \mathrm{C}$, whereas that of $\mathrm{L}_{2}$ was only $14.64 \% /{ }^{\circ} \mathrm{C}$, which was a difference of $28 \% /{ }^{\circ} \mathrm{C}$. This decrease was attributed to the previously described phenomenon. This result showed that the impregnation pretreatment effectively improved the thermal stability of the wood when heat-treated at high temperatures. 


\section{Smoke Density Test}

The low smoke emission of the control group can be attributed to the flashover and rapid combustion of wood after ignition, which emits a large amount of light and heat, and the smoke is mainly produced during the smoldering phase. The smoke density of Group $\mathrm{C}$ was smaller than that of the control group, and it burned rapidly and burned sufficiently after ignition. As shown by the results of the thermogravimetric analysis, its thermal stability decreased compared to the control group. It may be that during the heat treatment, part of the volatile extractives was volatilized and a small amount of components were decomposed. Consequently, the voids in the wood increased and the contact area of oxygen and wood components increased. Observing Group B, it can be seen that the amount of smoke increased significantly after the aluminum sulfate-sodium silicate synergistic impregnation treatment. This can be explained by the mechanism of precipitation products filling the voids of the wood, resulting in an increase in density, which made it very difficult for oxygen to penetrate the interior of the wood. The excessively incomplete combustion of the wood caused an increase in the amount of smoke, and the smoldering phase was significantly prolonged. But too much smoke is harmful to people's efforts to escape in the event of a fire. Compared with Group C, Group D had a longer smoldering stage, but it produced less smoke. This was due to the heat treatment at $180{ }^{\circ} \mathrm{C}$ which caused the surface of the samples to be charred, resulting in a reduction in the combustible components of the wood surface and isolating the wood components from further contact of the oxygen. Meanwhile, MDR of all samples was obviously less than 75 , which is in line with the standard (GB/T 8267-2007).

Table 2. Smoke Density of Samples with Different Treatment

\begin{tabular}{ccc}
\hline Expt. No & Maximum smoke density (MSD) & Smoke density rake (MDR) \\
\hline Group A & 5.43 & 3.69 \\
Group B & 46.54 & 26.35 \\
Group C & 4.06 & 3.26 \\
Group D & 6.97 & 5.21
\end{tabular}

Group A: control group; Group B: with aluminum-silicon impregnation/without heat treatment; Group C: without aluminum-silicon impregnation/with heat treatment; and Group D: with aluminumsilicon impregnation/with heat treatment

\section{Chemical Changes after Impregnation and Heat Treatment}

Fourier-transform infrared spectroscopy is a nondestructive and reliable method for studying the chemical constituents of lignocellulosic materials. The FTIR spectra of the samples are shown in Fig. 3. The peaks observed at $3420 \mathrm{~cm}^{-1}$ and $2920 \mathrm{~cm}^{-1}$ indicated that the stretching vibrations of $\mathrm{O}-\mathrm{H}$ and $\mathrm{C}-\mathrm{H}$ increased with the impregnation pretreatment (Sain and Panthapulakkal 2006; Ling et al. 2015; Guo et al. 2016). These changes revealed an increase in the hydroxyl group content. Moreover, the $\mathrm{C}-\mathrm{H}$ groups interacted strongly with water molecules via hydrogen bonding. The increase in this peak indicated that the single impregnation treatment can affect the hydrophobicity of wood (Pouzet et al. 2017). The prominent peak at $1745 \mathrm{~cm}^{-1}$ in the Paulownia wood was attributed to hemicellulosic acetyl and uronic ester groups or to the ester linkage of carboxylic groups of the ferulic and p-coumaric acids of lignin and/or hemicellulose (Himmelsbach et al. 2002; Lionetto et al. 
2012; Koutsianitis et al. 2015). As was observed after the impregnation treatment, this peak caused by $\mathrm{O}-\mathrm{H}$ stretching was considerably reduced. Lignin peaks were at $1595 \mathrm{~cm}^{-1}$ and $1506 \mathrm{~cm}^{-1}$ for $\mathrm{C}=\mathrm{C}$ stretching of the aromatic ring, and at $1463 \mathrm{~cm}^{-1}$ for $\mathrm{CH}_{3}$ bending. Typical bands assigned to cellulose were located at $1426 \mathrm{~cm}^{-1}$ and $1375 \mathrm{~cm}^{-1}$ for $\mathrm{CH}_{2}$ and $\mathrm{CH}$ bending, respectively, and at $1332 \mathrm{~cm}^{-1}$ and $897 \mathrm{~cm}^{-1}$ for hydroxyl bending, which also represented the state of the cellulose in the treated material (Temiz et al. 2010; Fackler et al. 2011). Unlike the peaks representing hemicelluloses, the variation in several peak intensities representing lignin and cellulosic components were small. The reason for this may be that the material was pre-soaked in an acidic aluminum sulfate solution. Thus, under the conditions of a low temperature and acid catalysis, part of the hemicellulose was hydrolyzed. However, the solid structure of the cellulose impeded decomposition at room temperature. Consequently, the impregnation treatment only slightly affected cellulose. This finding also showed that the use of the impregnation treatment increased the hygroscopicity of the material. Thus, it was concluded that this technique should be combined with other methods for further material processing to reduce the hygroscopicity and improve the dimensional stability.

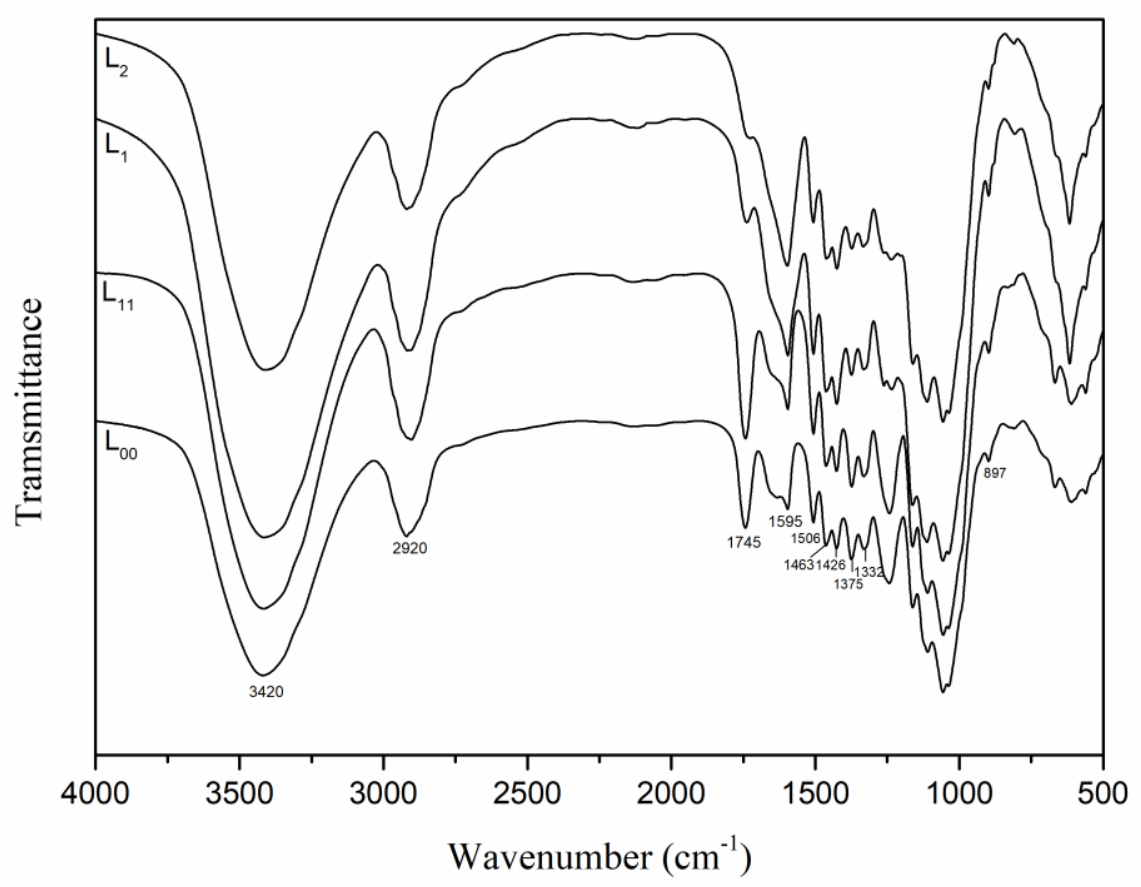

Fig. 3. FTIR spectra of the samples; $L_{00}$ : control group; $L_{1}$ : with aluminum-silicon impregnation/without heat treatment; $L_{11}$ : without aluminum-silicon impregnation/with heat treatment; and $\mathrm{L}_{2}$ : with aluminum-silicon impregnation/with heat treatment

By comparing the samples in groups $L_{1}$ and $L_{2}$, it was found that after the heat treatment, the free hydroxyl group content of the samples pretreated with the aluminumsilicon synergistic impregnation treatment declined substantially. This result suggested that the high-temperature heat treatment is an effective and environmentally friendly method for reducing the free hydroxyl groups resulting from the impregnation treatment. Moreover, given that both $\mathrm{L}_{1}$ and $\mathrm{L}_{2}$ groups underwent the aluminum-silicon impregnation treatment, the peak intensity at $1745 \mathrm{~cm}^{-1}$ was small, although it was smaller for $\mathrm{L}_{2}$. This difference indicated that high-temperature heat treatment could further aggravate the 
degradation of hemicellulose. The peaks representing cellulose and lignin changes were still small, which enhanced the wood hydrophobicity. Furthermore, the aluminum-silicon synergistic impregnation treatment combined with heat treatment at $180{ }^{\circ} \mathrm{C}$ only slightly affected the cellulose and lignin components, which had a considerable effect on the wood strength.

\section{Morphology and Mechanism}

\section{SEM analysis}

Figure 4 shows the SEM images of the samples before and after the impregnation treatment with aluminum-silicon. The SEM images of the control group and group pretreated with aluminum-silicon impregnation and without a high-temperature heat treatment are presented above. Compared with that of the control group, the aluminum sulfate was mainly concentrated in the vessel lumen of the Paulownia wood and the distribution was uniform. Some precipitation was observed in the axial parenchyma, but it was lower than the content in the vessel.
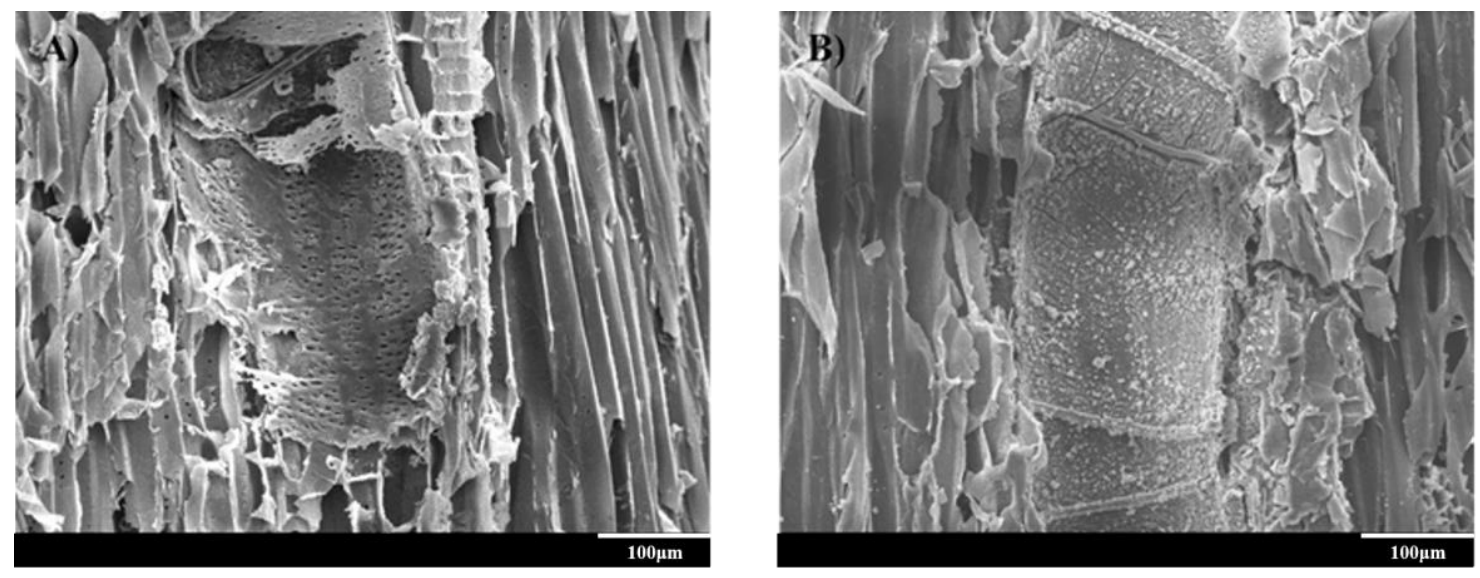

Fig. 4. SEM images of the samples; $\mathrm{A}$ : control group; and B: with aluminum-silicon impregnation

\section{Mechanism}

The influencing mechanism of the combined aluminum-silicon impregnation and heat treatment on the Paulownia wood is described in Fig. 5. The wood cell wall is mainly composed of cellulose, hemicellulose, and lignin. During the impregnation process, the aluminum sulfate was preferentially impregnated. The $\mathrm{Al}^{3+}$ ions entered the interior of the wood through wood pits and other water passages, while some $\mathrm{Al}^{3+}$ ions entered into the cell walls via chemical bonding. The subsequently impregnated sodium silicate combined with the aluminum sulfate through the adsorption bridging reaction and produced a hightemperature-resistant precipitation product that was uniformly distributed inside of the wood. However, the hygroscopicity of the wood after impregnation was increased. During the preheating process $\left(80^{\circ} \mathrm{C}\right)$, part of the hemicelluloses in the impregnation-treated group underwent thermal degradation at a low temperature and acidic conditions, which generated a small amount of acid residues in the wood. Therefore, during heat treatment at $180{ }^{\circ} \mathrm{C}$, the wood rapidly formed char layers on the surface during catalysis of the trace acid. This insulated the internal material from further contact with oxygen. At the same time, the precipitate effectively protected the carbon layer and trapped the wood. Therefore, 
this combined treatment not only improved the wood thermal stability, but it also reduced the moisture absorption.

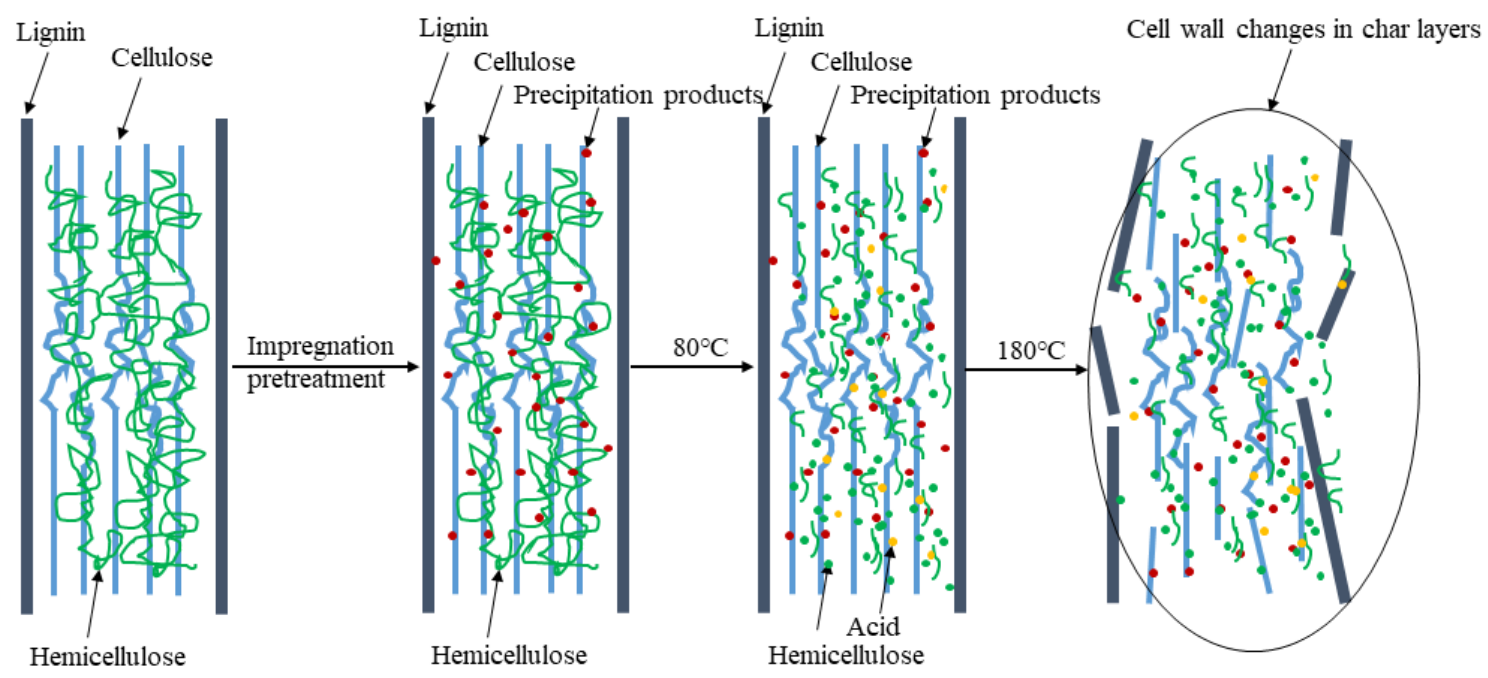

Fig. 5. Influencing mechanism of the combined aluminum-silicon impregnation and high temperature heat treatment on the Paulownia wood

\section{CONCLUSIONS}

1. The effect of aluminum-silicon synergistic impregnation had a noticeable effect when the wood was first impregnated with aluminum sulfate and then immersed in the sodium silicate solution. The wood weight gain rate reached $33.8 \%$.

2. The aluminum-silicon synergistic flame retardant system effectively improved the thermal stability of the wood. After the aluminum-silicon synergistic impregnation treatment, the thermal degradation temperature moved slightly to a low-temperature region, but the thermal degradation rate decreased remarkably.

3. The impregnation treatment by itself can prolong the smoldering phase of the wood, but the amount of the smoke increased. However, the amount of smoke was reduced in the case of the aluminum-silicon impregnation treated sample that also had been heat treated. This indicates that the impregnation-heat treatment method can effectively reduce the amount of smoke under the guarantee of better thermal stability.

\section{ACKNOWLEDGMENTS}

This study was financially supported by the Major Scientific and Technological Achievements Incubation Projects in Beijing Forestry University (2017CGP014), the Fundamental Research Funds for the Central Universities of China (2015ZCQ-CL-01), and the Hot Tracking Project in Beijing Forestry University (2017BLRD04). 


\section{REFERENCES CITED}

Benalycherif, M. L., and Girault, C. (2010). "Treatment of paper and pulp mill effluent by coagulation," Environmental Technology. 31, 357-363. DOI:

$10.1080 / 09593330903486665$

Cai, L. (2015). Preparation and Fire Retardant Mechanism of Recycled Paper Foaming Material with Silicon-alumium Compounds, Master's Thesis, Fujian Agriculture and Forestry University, Fuzhou, China.

Candan, Z., Korkut, S., and Unsal, O. (2013). "Effect of thermal modification by hot pressing on performance properties of paulownia wood boards," Ind. Crop. Prod. 45, 461-464. DOI: 10.1016/j.indcrop.2012.12.024

Canosa, G., Alfieri, P. V., and Giudice, C. A. (2011). "Nano lithium silicates as flameretardant impregnants for Pinus radiata," J. Fire Sci. 29(5), 431-441.

DOI: $10.1177 / 0734904111404652$

Chen, L., Xie, G., Ma, H., He, X., and Zhang, Y. (2012). "Study on the influence of accelerated heat-treatment on wood color changes," Guangdong Forestry Science and Technology.

Chen, Y., Cai, T., Dang, B., Wang, H., Xiong, Y., Yao, Q., Wang, C., Sun, Q., and Jin, C. (2018). "The properties of fibreboard based on nanolignocelluloses $/ \mathrm{CaCO}_{3} / \mathrm{PMMA}$ composite synthesized through mechano-chemical method," Sci. Rep.-UK 8.

DOI: $10.1038 / \mathrm{s} 41598-018-23497-\mathrm{x}$

Cui, W., Zhang, N., Xu, M., and Cai, L. (2017). “Combined effects of ZnO particle deposition and heat treatment on dimensional stability and mechanical properties of poplar wood," Sci. Rep.-UK 7. DOI: 10.1038/s41598-017-10606-5

Elvira-León, J. C., Chimenos, J. M., Isábal, C., Monton, J., Formosa, J., and Haurie, L. (2016). "Epsomite as flame retardant treatment for wood: Preliminary study," Constr. Build. Mater. 126, 936-942. DOI: 10.1016/j.conbuildmat.2016.09.107

Fackler, K., Stevanic, J. S., Ters, T., Hinterstoisser, B., Schwanninger, M., and Salmén, L. (2011). "FT-IR imaging microscopy to localise and characterise simultaneous and selective white-rot decay within spruce wood cells," Holzforschung 65(3), 411-420. DOI: 10.1515/HF.2011.048

Furuno, T., Uehara, T., and Jodai, S. (1993). "Combinations of wood and silicate, 3: Some properties of wood-mineral composites using the water glass-boron compound system," Journal of the Japan Wood Research Society. 39, 561-570. DOI: $10.2472 /$ jsms.48.245

Gao, J., Kim, J. S., Terziev, N., and Daniel, G. (2016). "Decay resistance of softwoods and hardwoods thermally modified by the Thermovouto type thermo-vacuum process to brown rot and white rot fungi," Holzforschung 70(9), 877-884. DOI: $10.1515 / \mathrm{hf-}$ 2015-0244

GB/T 8627-2007. "The method for density of smoke from the buring or decomposition of building materials"

Gong, M., Cheng, R., Song, Y., Zhou, H. (2013). "Methods of Inorganic Modification of Wood," Forest Engineering.

Guo, X., Cao, J., Peng, Y., and Liu, R. (2016). "Incorporation of microencapsulated dodecanol into wood flour/high-density polyethylene composite as a phase change material for thermal energy storage," Mater. Design 89, 1325-1334.

DOI: 10.1016/j.matdes.2015.10.068

Hamdani, S., Longuet, C., Perrin, D., Lopez-Cuesta, J. M., and Ganachaud, F. (2009). 
"Flame retardancy of silicone-based materials," Polym. Degrad. Stabil. 94(4), 465495. DOI: 10.1016/j.polymdegradstab.2008.11.019

Heng, L. (2009). Study on Modifying Populus Wood by Silicates, Master's Thesis, Northeast Forestry University, Harbin, China.

Hidayat, W., Qi, Y., Jang, J. H., Febrianto, F., and Kim, N. H. (2017). "Effect of mechanical restraint on drying defects reduction in heat-treated okan wood," BioResources 12(4), 7452-7465. DOI: 10.15376/biores.12.4.7452-7465

Himmelsbach, D. S., Khalili, S., and Akin, D. E. (2002). "The use of FT-IR microspectroscopic mapping to study the effects of enzymatic retting of flax (Linum usitatissimum L) stems," J. Sci. Food Agr. 82(7), 685-696. DOI: 10.1002/jsfa.1090

Hosseinpourpia, R., Adamopoulos, S., and Mai, C. (2018). "Effects of acid pre-treatments on the swelling and vapor sorption of thermally modified Scots pine (Pinus sylvestris L.) wood," BioResources 13(1), 331-345. DOI: 10.15376/biores.13.1.331-345

Hu, F. (2012). Preliminary Research on the Flame Retardant Effect and Mechanism of the Preparation for Paper which Coating by Compounded with Hydroxide System of Sodium Aluminum Silicate, Master's Thesis, Guangxi University, Nanning, China.

Humar, M., Kržišnik, D., Lesar, B., Thaler, N., Ugovšek, A., Zupančič, K., and Žlahtič, M. (2016). "Thermal modification of wax-impregnated wood to enhance its physical, mechanical, and biological properties," Holzforschung 71(1), 57-64.

DOI: $10.1515 / \mathrm{hf}-2016-0063$

Irfan, M., Butt, T., Imtiaz, N., Abbas, N., Khan, R.A., and Shafique, A. (2013). "The removal of COD, TSS and colour of black liquor by coagulation-flocculation process at optimized pH, settling and dosing rate," Arabian Journal of Chemistry. 48, 11031110.e4. DOI: 10.1016/j.arabjc.2013.08.007

Jebrane, M., Pockrandt, M., Cuccui, I., Allegretti, O., Uetimane Jr., E., and Terziev, N. (2018). "Comparative study of two softwood species industrially modified by Thermowood $\AA$ and thermo-vacuum process," BioResources 13(1), 715-728. DOI: $10.15376 /$ biores.13.1.715-728

Jiang, J., Cao, J., and Wang, W. (2018). "Characteristics of wood-silica composites influenced by the $\mathrm{pH}$ value of silica sols," Holzforschung 72(4), 311-319. DOI: $10.1515 / \mathrm{hf}-2017-0126$

Koutsianitis, D., Mitani, C., Giagli, K., Tsalagkas, D., Halász, K., Kolonics, O., Gallis, C., and Csóka, L. (2015). "Properties of ultrasound extracted bicomponent lignocellulose thin films," Ultrason. Sonochem. 23, 148-155. DOI: 10.1016/j.ultsonch.2014.10.014

Li, T., Cheng, D.-1., Wålinder, M. E. P., and Zhou, D.-g. (2015). "Wettability of oil heattreated bamboo and bonding strength of laminated bamboo board," Ind. Crop. Prod. 69, 15-20. DOI: 10.1016/j.indcrop.2015.02.008

Liao, Y.-F., Ma, X.-Q., and Sun, Y.-M. (2008). "Kinetics of pyrolysis and metal-salt catalized pyrolysis of wood," Chemistry and Industry of Forest Products 28, 45-50.

Liang, Y. S., Jian-Ying, Y. U., Wen-Zu, L. I., and Yao, T. T. (2013). "Preparation and properties of flame-retardant bitumen with aluminium trihydroxide/montmorillonite," Journal of Wuhan University of Technology.

Ling, Z., Ji, Z., Ding, D., Cao, J., and Xu, F. (2015). "Microstructural and topochemical characterization of thermally modified poplar (Populus cathayaha) cell wall," BioResources 11(1), 786-799. DOI: 10.15376/biores.11.1.786-799

Lionetto, F., Del Sole, R., Cannoletta, D., Vasapollo, G., and Maffezzoli, A. (2012). "Monitoring wood degradation during weathering by cellulose crystallinity," 
Materials 5(10), 1910-1922. DOI: 10.3390/ma5101910

Lowden, L. A., and Hull, T. R. (2013). "Flammability behaviour of wood and a review of the methods for its reduction," Fire Sci. Rev. 2(4). DOI: 10.1186/2193-0414-2-4

Lu, K., White, R. H., Fu, F., Hou, J., Zhang, Y., Gribbins, N., and Cai, Z. (2015). "Reinforced hybrid wood-aluminum composites with excellent fire performance," Holzforschung 69(8), 1027-1037. DOI: 10.1515/hf-2014-0099

Nishimura, H., Kamiya, A., Nagata, T., Katahira, M., and Watanabe, T. (2018). "Direct evidence for $\alpha$ ether linkage between lignin and carbohydrates in wood cell walls," Sci. Rep.-UK 8. DOI: 10.1038/s41598-018-24328-9

Ogiso, K., and Saka, S. (1994). "Wood-inorganic composites prepared by Sol-Gel process, 4: Effects of chemical bonds between wood and inorganic substances on property enhancement," J. Jpn. Wood Res. Soc. 40(10), 1100-1106.

Okon, K. E., Lin, F., Chen, Y., and Huang, B. (2017). "Effect of silicone oil heat treatment on the chemical composition, cellulose crystalline structure and contact angle of Chinese parasol wood," Carbohydr. Polym. 164, 179-185.

DOI: 10.1016/j.carbpol.2017.01.076

Park, H.-J., Wen, M.-Y., Cheon, S.-H., Kang, C.-W., and Matsumura, J. (2015). “Fire retardant performance and thermal degradation of Korean pine treated with fire retardant chemical," Faculty of Agriculture Kyushu University 60(1), 183-189.

Pereyra, A. M., and Giudice, C. A. (2009). "Flame-retardant impregnants for woods based on alkaline silicates," Fire Safety J. 44(4), 497-503.

DOI: 10.1016/j.firesaf.2008.10.004

Pouzet, M., Dubois, M., Charlet, K., and Béakou, A. (2017). "The effect of lignin on the reactivity of natural fibres towards molecular fluorine," Mater. Design 120, 66-74. DOI: $10.1016 /$ j.matdes.2017.01.086

Qu, H., Wu, W., Jiao, Y., Xie, J., and Xu, J. (2011). "Investigation on the thermal decomposition and flame retardancy of wood treated with a series of molybdates by TG-MS," J. Therm. Anal. Calorim. 105(1), 269-277. DOI: 10.1007/s10973-0111313-3

Sain, M., and Panthapulakkal, S. (2006). "Bioprocess preparation of wheat straw fibers and their characterization," Ind. Crop. Prod. 23(1), 1-8.

DOI: 10.1016/j.indcrop.2005.01.006

Schwartz, M., Perrot, T., Aubert, E., Dumarçay, S., Favier, F., Gérardin, P., MorelRouhier, M., Mulliert, G., Saiag, F., Didierjean, C., et al. (2018). "Molecular recognition of wood polyphenols by phase II detoxification enzymes of the white rot Trametes versicolor," Sci. Rep.-UK 8. DOI: 10.1038/s41598-018-26601-3

Seo, H., Kim, N., Jo, J., and Lee, M. (2018). "Fire properties of Pinus densiflora utilizing fire-retardant chemicals based on borate and phosphorus (II) - Thermal and gas emission characteristics," BioResources 13(1), 506-521.

DOI: 10.15376/biores. 13.1.506-521

Skaar, C. (1988). Wood-water Relations, Springer-Verlag, Berlin, Germany.

Temiz, A., Terziev, N., Jacobsen, B., and Eikenes, M. (2010). "Weathering, water absorption, and durability of silicon, acetylated, and heat-treated wood," J. Appl. Polym. Sci. 102(5), 4506-4513. DOI: 10.1002/app.24878

Wang, N., Liu, Y., Xu, C., Liu, Y., and Wang, Q. (2017). "Acid-base synergistic flame retardant wood pulp paper with high thermal stability," Carbohydr. Polym. 178, 123130. DOI: 10.1016/j.carbpol.2017.08.099

Wang, Y., Zhang, Z., Fan, H., and Wang, J. (2018). "Wood carbonization as a protective 
treatment on resistance to wood destroying fungi," Int. Biodeter. Biodegr. 129, 42-49. DOI: 10.1016/j.ibiod.2018.01.003

Yang, Y., Dong, C., Luo, B., Chen, T., and Lu, J. (2018). “Characterization of wood surface elemental compositions after thermo-vacuum treatment and superheatedsteam heat treatment," BioResources 13(1), 1895-1908.

DOI: 10.15376/biores.13.1.1895-1908

Zhao, Q., and Deng, G.-1. (2006). "The application of flame retardant in paper industry," China Pulp and Paper Industry.

Zhao, Z. M., and Xu, S. L. (2018). "Application of refractory materials in brick kilns(I)," Brick-Tile 4, 36-39. DOI: 10.16001/j.cnki.1001-6945.2018.04.011

Zhou, P., Zhang, Z. Y., and Liang, S. (2000). "Combination of Populus tomentosa wood and inorganic substances," J. Beijing Forestry University 56(6), 39-42.

DOI: $10.13332 /$ j.1000-1522.2000.06.010

Article submitted: August 17, 2018; Peer review completed: November 7, 2018; Revised version received: November 14, 2018; Accepted: November 15, 2018; Published:

November 20, 2018.

DOI: $10.15376 /$ biores.14.1.349-362 